\section{$p l a n+a$}

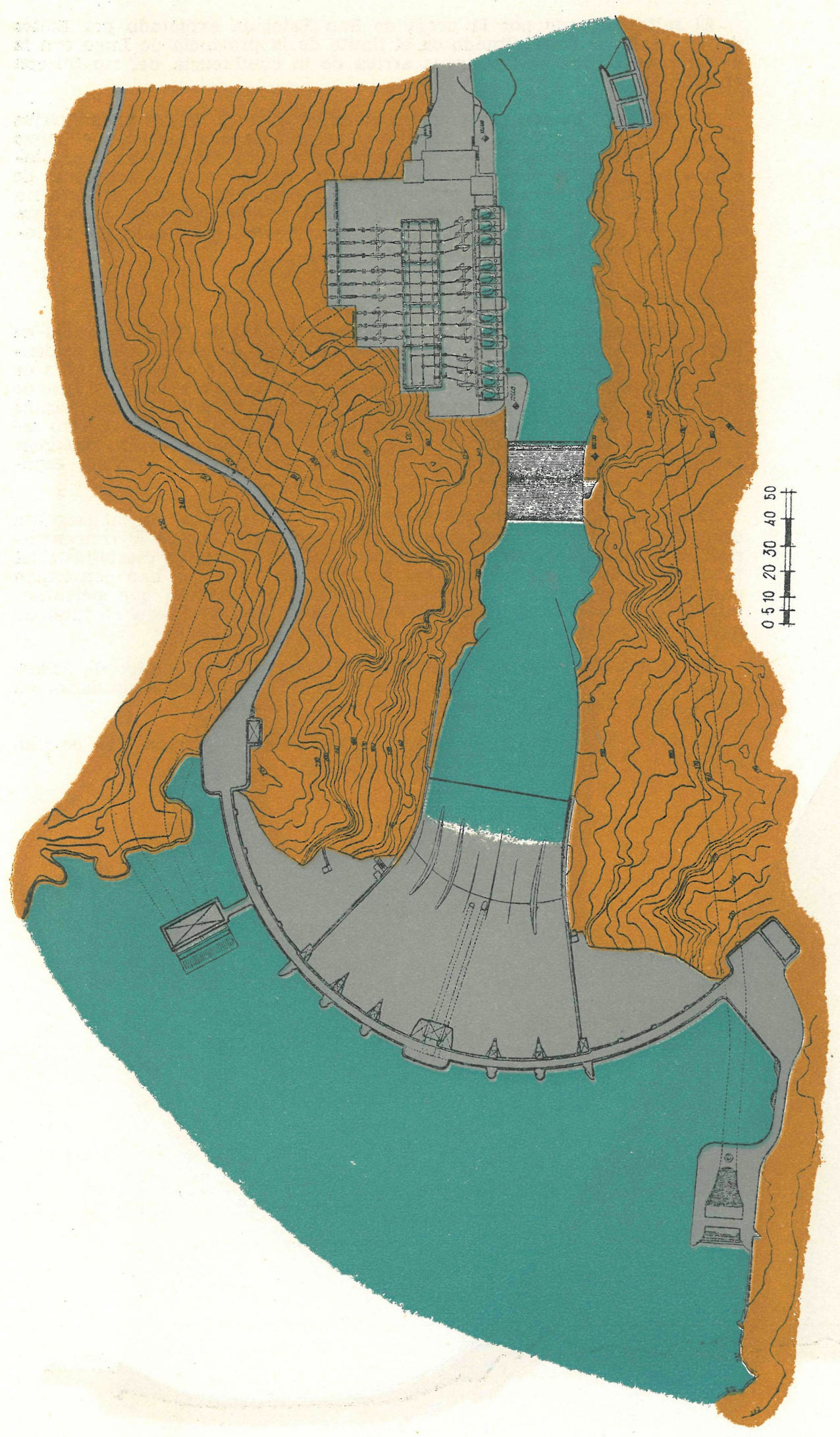

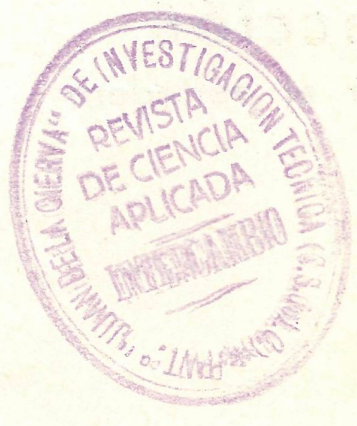

$531 \cdot 23$

\title{
presa de San Esteban
}

S IN O P S I S

En el número 73 de esta revista se publicó un artículo, que trataba létricos de la in este trabajo se hace inica de San Esteban, obra que, por altura de salto, caudales disponibles yembalse, és la de mayor ducción de las de la referida cuenca. Su proyección en planta e circular, tipo gravedad, de $115 \mathrm{~m}$ de altura, y su embalse, de 213 millones de metros cúbicos. 
sección

\section{por el vertedero}

\section{Generalidades}

El salto formado por la presa de San Esteban, explotado por Saltos del Sil, S. A., se halla situado en el límite de la provincia de Lugo con la de Orense, a unos $10 \mathrm{~km}$ aguas arriba de la confluencia del río Sil con el Miño.

El embalse formado por la presa se extiende unos $40 \mathrm{~km}$ aguas arriba de la obra, dentro del vaso angosto y acantilado que presenta el curso natural del río, accidente tectónico desfavorable para las grandes acumulaciones de agua. La regulación del río se ha dejado para otras presas de aguas arriba que se hallan mejor situadas para esta finalidad. Esto no obstante, su embalse permite establecer una reserva suficiente para una explotación regular y ordenada, ya que, del volumen embalsado, 195 millones de metros cúbicos son utilizables.

\section{Descripción de la obra}

La presa de San Esteban, tipo gravedad, en arco de $120 \mathrm{~m}$ de radio en el paramento vertical de aguas arriba, tiene $115 \mathrm{~m}$ de altura sobre cimientos; en la parte central se ha construído un aliviadero de $4.500 \mathrm{~m}^{3} / \mathrm{s}$ de capacidad, formado por seis pasas de $15 \mathrm{~m}$ de luz cada una y $6,2 \mathrm{~m}$ de altura, cuya regulación de paso se lleva a cabo por medio de otras tantas compuertas de sector. A este aliviadero principal le complementa otro secundario en túnel, situado en la margen derecha, que permite desaguar pequeñas avenidas y regular los niveles de embalse para posibles reparaciones de las compuertas del aliviadero central.

Debido a la forma circular de la presa y la estrechez de la garganta de cerrada de la presa, las láminas vertientes de las pasas se concentrarían en el pie del aliviadero, y pondrían en grave riesgo la estabilidad del fondo del cuenco de amortizacion; en vista de lo cual, se han construído unos tabiques guías en la parte inferior del aliviadero que permiten romper la referida convergencia. Estas provisiones han sido el fundado motivo de construir la central un poco más aguas abajo.

En la parte superior de la presa se ha construído un camino de acceso a las casas de mandos de las compuertas del aliviadero secundario, en túnel, de la margen derecha.

La presa dispone de una serie de galerías de inspección, que se han situado a niveles convenientemente elegidos. 


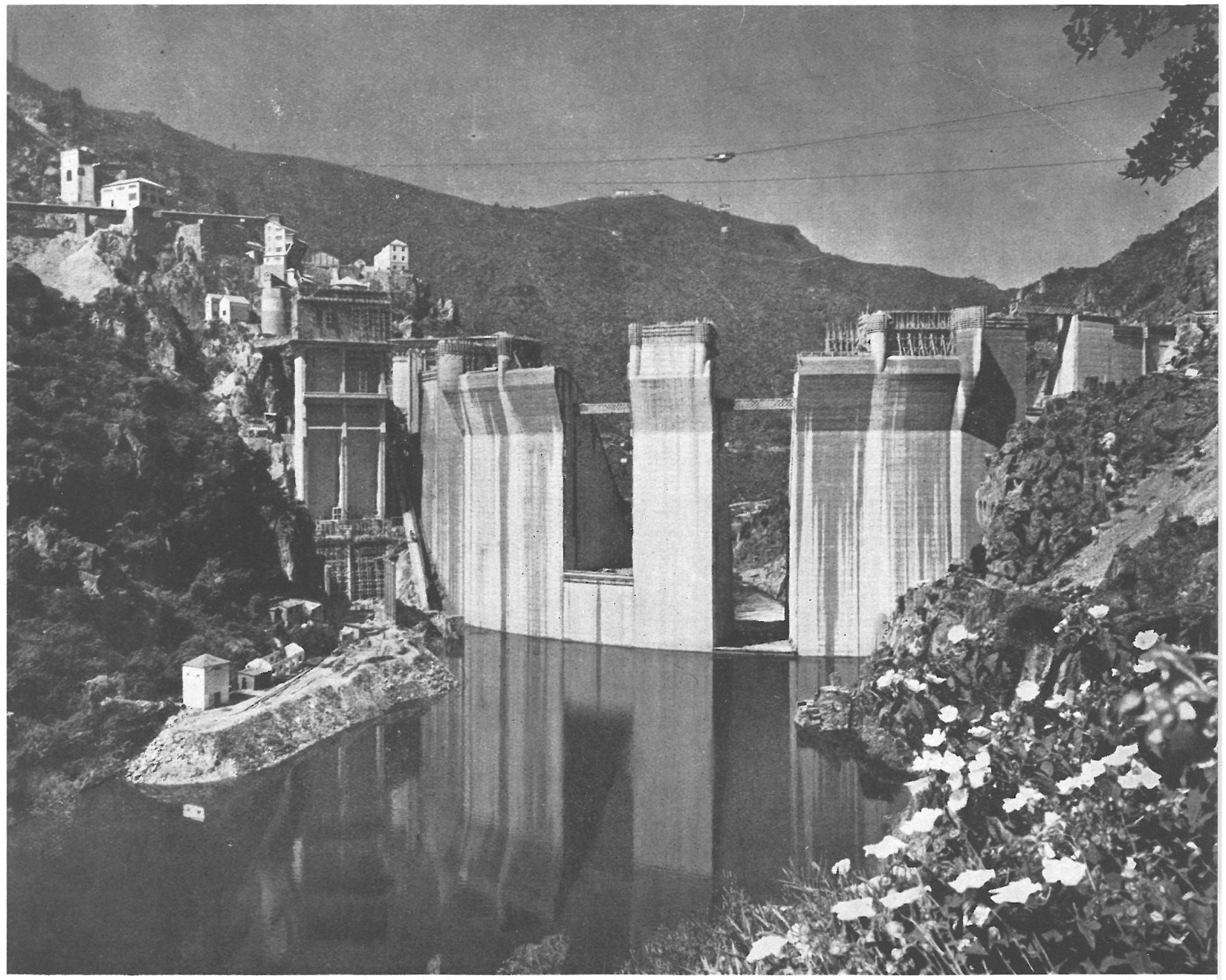

Antes de terminar la presa se empezó a embalsar agua.

\section{Toma de agua}

La toma de agua para la central está constituída por una torre independiente de la presa, de la que parten dos galerías de $6,80 \mathrm{~m}$ de diámetro cada una, que, a su vez, se bifurcan en otras dos de $4,20 \mathrm{~m}$ de diámetro. El revestimiento de las dos galerías de toma en túnel es de hormigón armado, mientras que las otras cuatro, que constituyen las tuberías forzadas propiamente dichas, se han reforzado con virolas de chapa de acero de $34 \mathrm{~mm}$ de espesor.

Al pie de la torre de toma se han montado $400 \mathrm{~m}^{2}$ de rejillas de protección y, seguidamente, las dos compuertas de paso para las galerías de toma, cuya sección por unidad es de $5 \mathrm{~m}$ de ancho por $8,25 \mathrm{~m}$ de altura. 


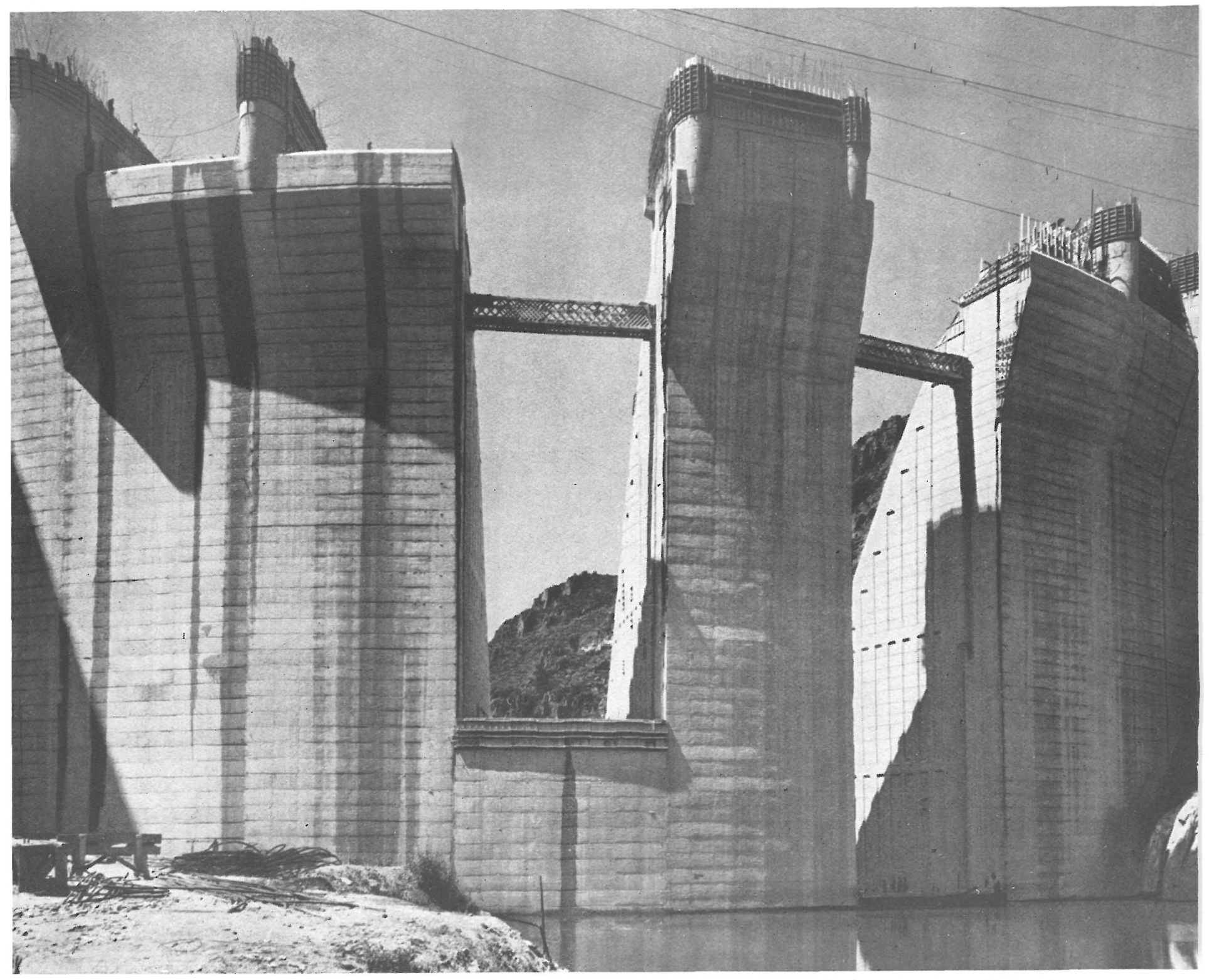

El empuje total sobre cada una de estas compuertas es de 3.000 toneladas cuando el embalse está lleno. En el interior de la torre, y en la parte superior, se han instalado los mecanismos y mandos de maniobra de las compuertas, y, además, un acceso para el registro e inspección de las propias compuertas.

\section{Central generadora}

En la central de San Esteban se han instalado cuatro grupos generadores con una potencia total de $330.000 \mathrm{KVA}$. Cada grupo está constituído por una turbina Francis, de eje vertical, de $90.700 \mathrm{CV}$ de potencia, que aprovecha un salto de $104 \mathrm{~m}$ y $75 \mathrm{~m}^{3} / \mathrm{s}$ de caudal en plena carga.

La presa de San Esteban, sobre el río Sil, a pesar de su gran resistencia, presenta el bloque central poderosa atalaya, que la prudencia la rodea de un doble portillo para el paso de una posible irrupcion de las procelosas aguas curso. 


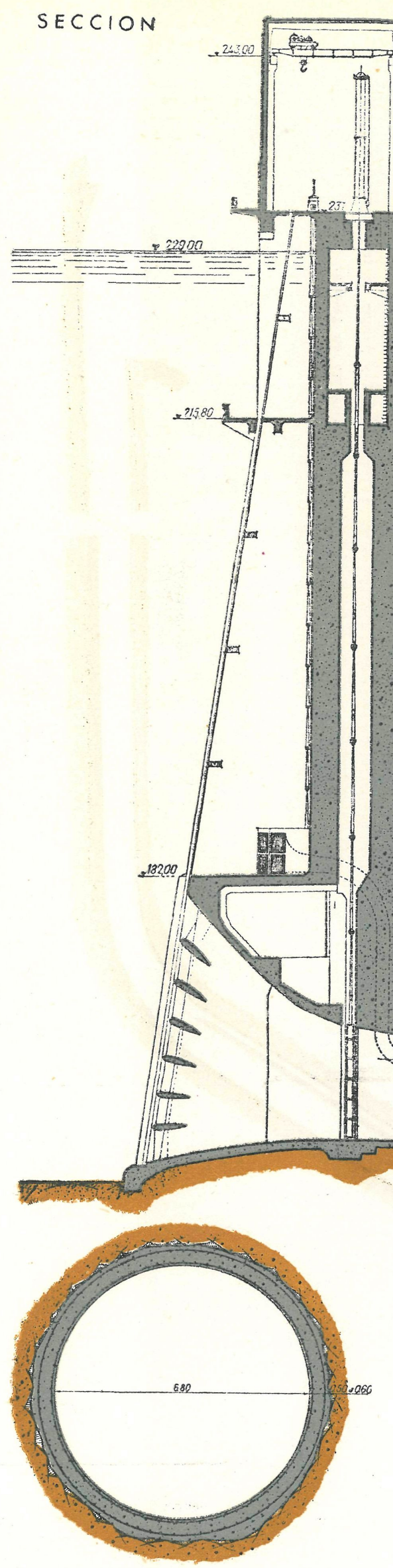

CONDUCCIONES EN TUNEL
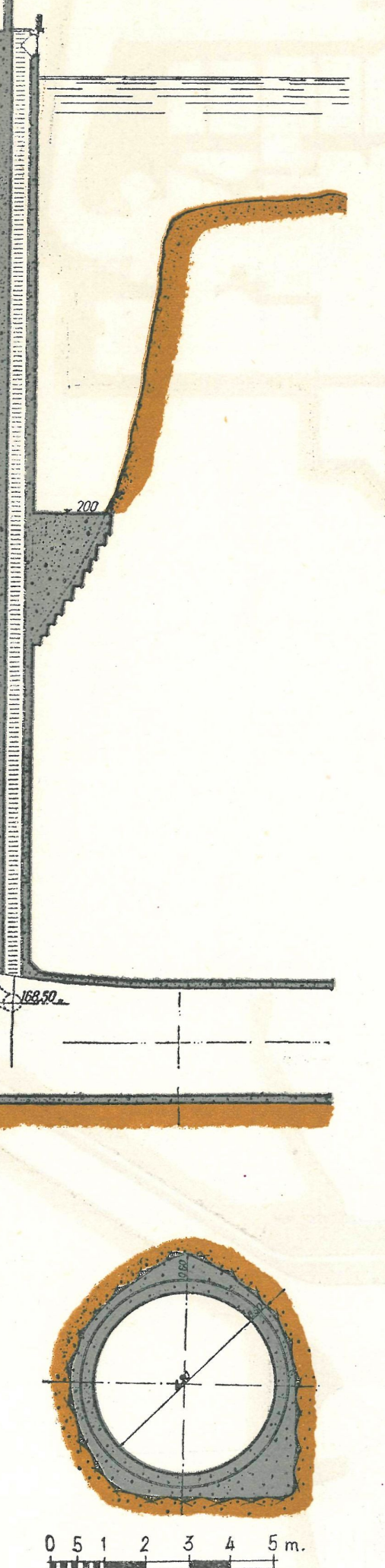

TUBERIA EN TUNEL

\section{toma de aguas}

Cada turbina mueve un alternador de $82.500 \mathrm{KVA}$ que gira a razón de $214 \mathrm{rpm}$.

La tensión de generación es de $15.000 \mathrm{~V}$. que se eleva a $220.000 \mathrm{~V}$ por grupos de transformadores monofásicos, instalados en la cubierta de la central por falta material de espacio.

A estas instalaciones electromecánicas las complementan dos grupos auxiliares: uno de $1.350 \mathrm{KVA}$, que se alimenta con las aguas derivadas de las tuberías principales; y otro, que aprovecha las aguas de un arroyo que vierte al embalse y que forma un salto de $310 \mathrm{~m}$ de altura.

\section{Construcción de la obra}

Para dejar en seco el lugar de ubicación de la presa, se procedió a derivar las aguas del río por medio de una galería de $9 \mathrm{~m}$ de ancho por 8 de altura y una presa de $27,5 \mathrm{~m}$ de altura. Aguas abajo del lugar de la presa se levantó una segunda ataguía, constituída por un dique construído por los procedimientos Prepakt, es decir, vertiendo piedra suelta, que después se inyectaba con mortero.

Esta galería de derivación permitió un desagüe de unos $600 \mathrm{~m}^{3} / \mathrm{s}, \mathrm{y}$, después de terminar su objeto inicial, se la aprovechó para el desagüe del aliviadero complementario en túnêi.

El hormigonado se realizó por medio de dos blondines de gran capacidad, instalados de tal forma que cubrían todo el perímetro de la presa, los que se alimentaban por una central hormigonera de dosificación automática, instalada a pie de obra.

El procedimiento constructivo empleado consistió en la clásica formación de bloques, dejando los no menos conocidos portillos entre ellos, para prevenirse contra la emergencia de posibles avenidas peligrosas. Las galerías se revistieron de hormigón utilizando las bombas hormigoneras accionadas con aire comprimido, y la central, auxiliándose de grúas.

Los áridos se arrancaron de una cantera próxima, situada a una cota suficientemente elevada para permitir su manipulación, por gravedad, en las instalaciones de machaqueo, molienda, clasificación y almacenamiento. Tanto las operaciones de arranque como las de transporte del frente de extracción a la estación de machaqueo y pasos intermedios de la clasificación, se realizaron utilizando una mecanización moderna, es decir, máquinas perforadoras, volquetes metálicos de gran capacidad y cintas transportadoras.

Alzado de la torre de toma de aguas mostrando la rejilla de protección, compuerta, cámara de acceso y secciones de las dos galerías de toma y de las cuatro tuberias forzadas. 


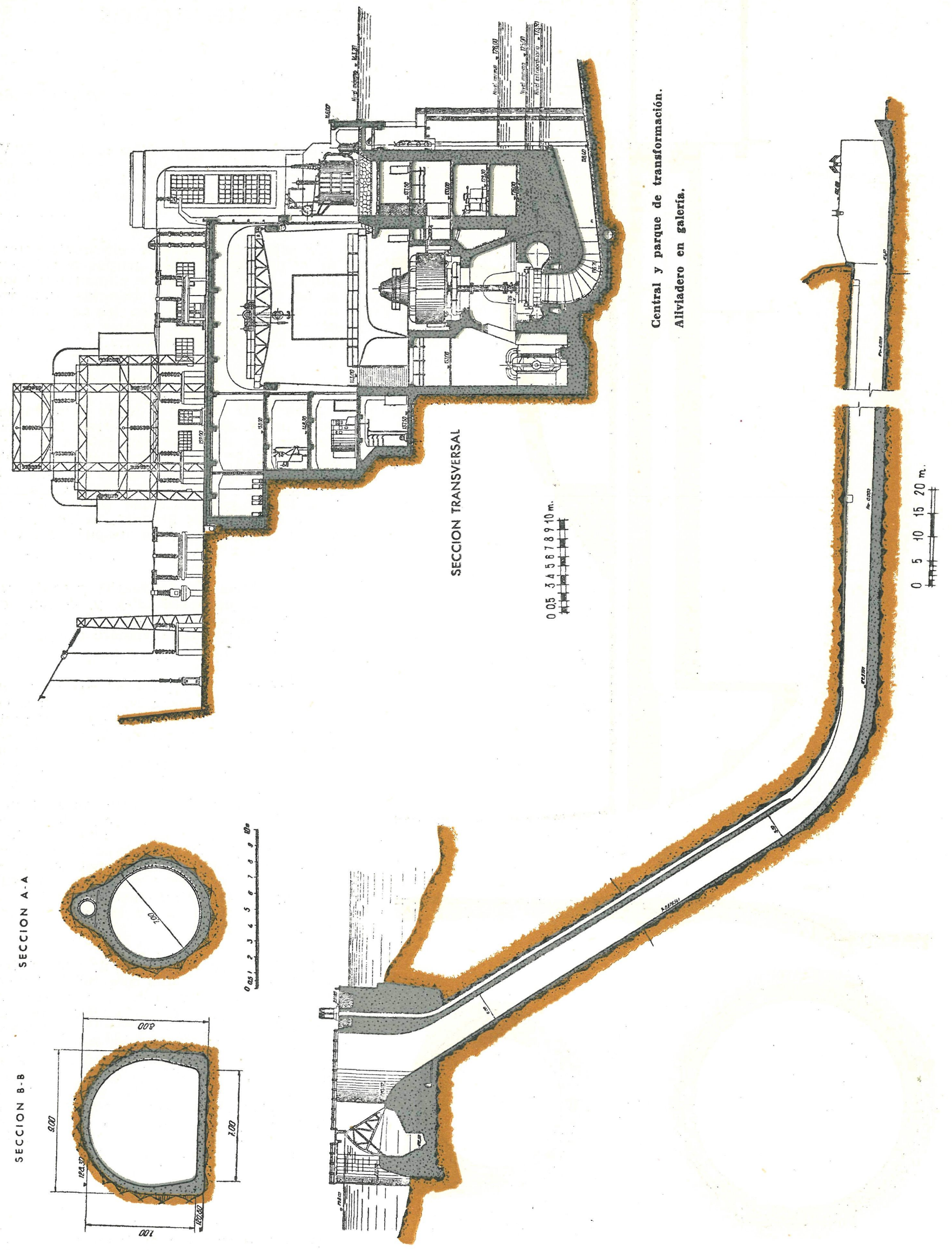




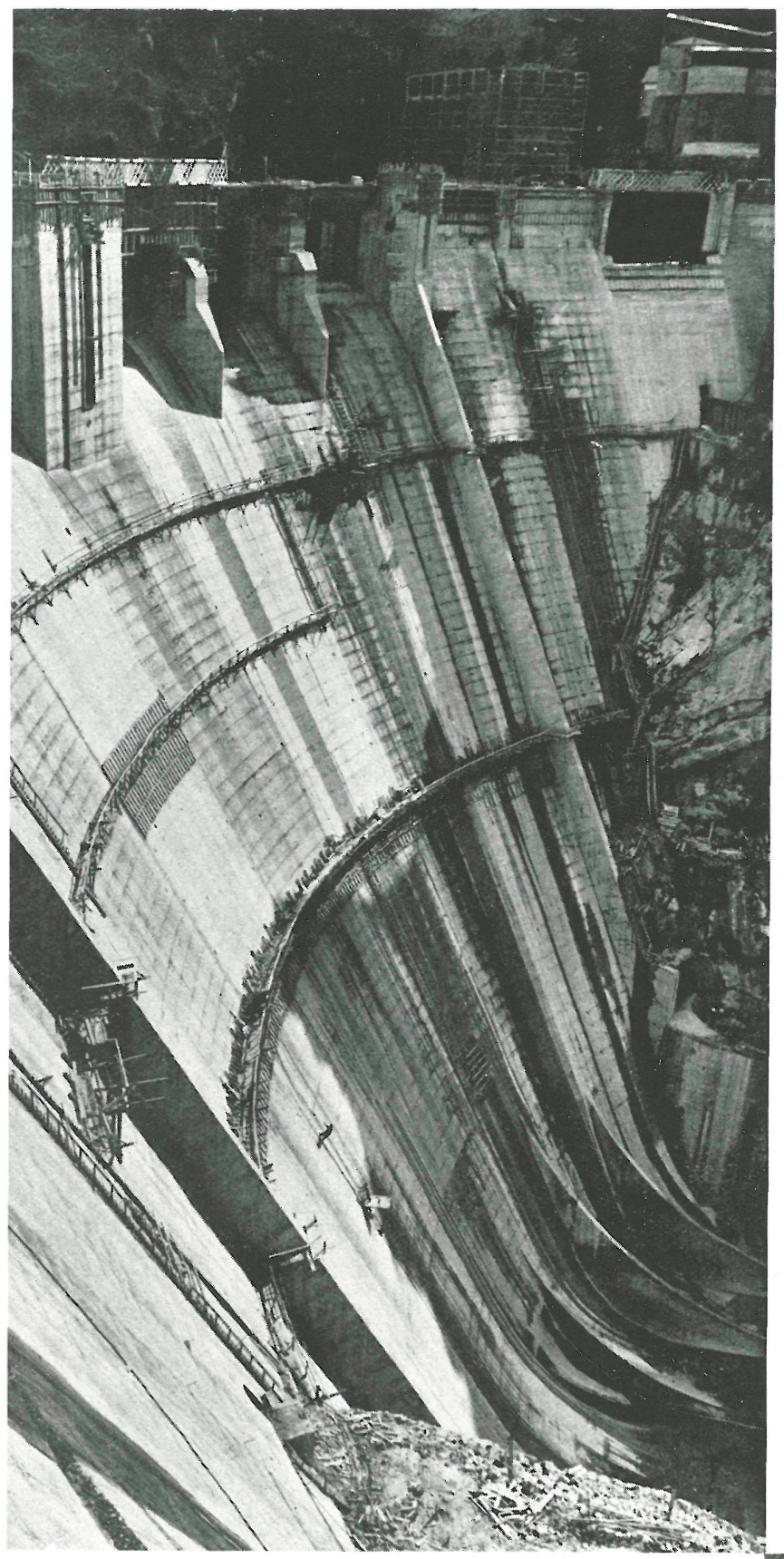

construcción
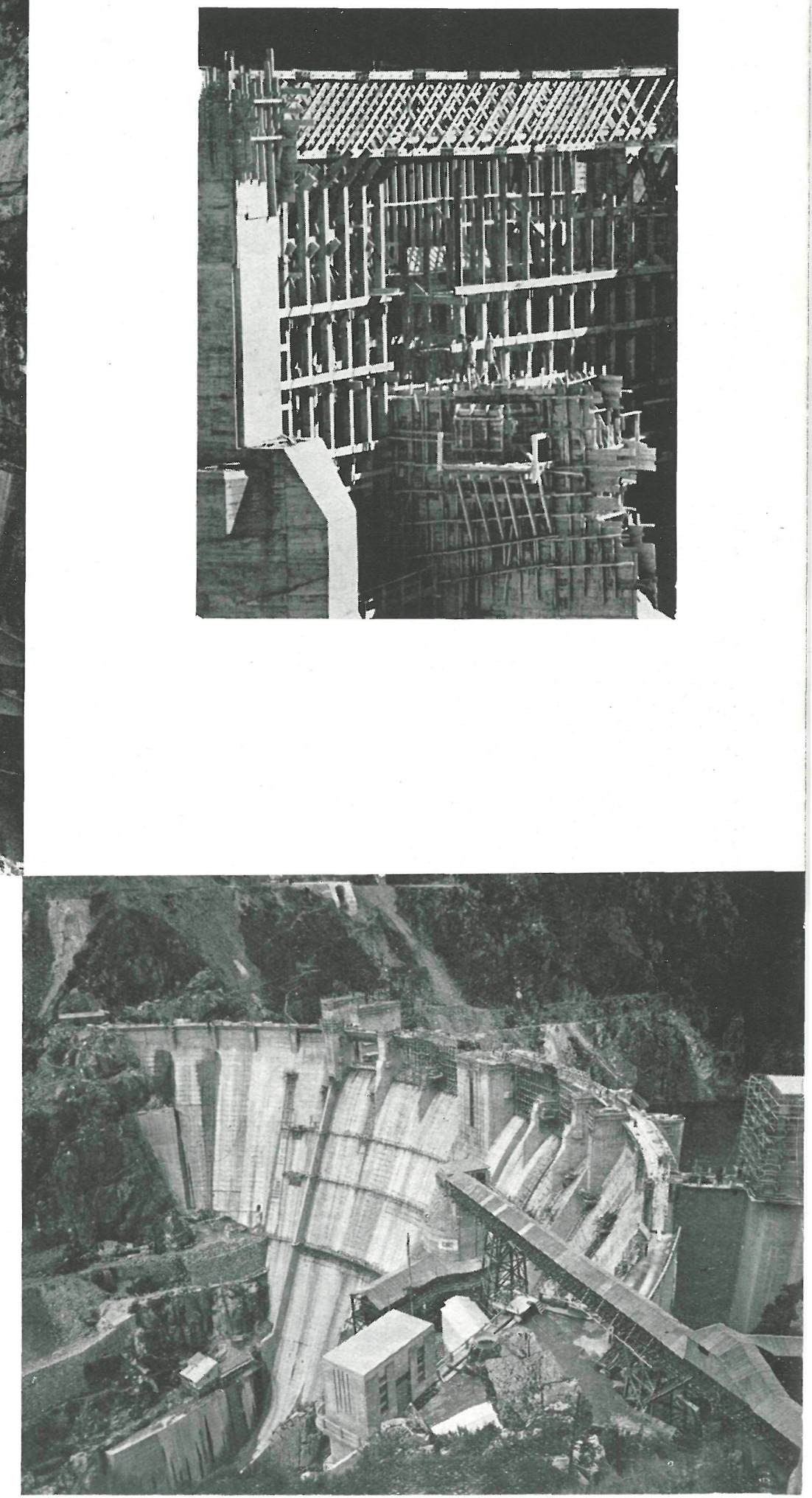

Vista del paramento de aguas abajo de la presa, en el que se pueden apreciar los tabiques guias

Como se puede observar por las líneas perfectas de la aristas y paños de hormigón, se encofró con meticulosida y cuidado.

Aspecto general de la presa, en vías de terminación, y parcial de la torre de toma de agua. 


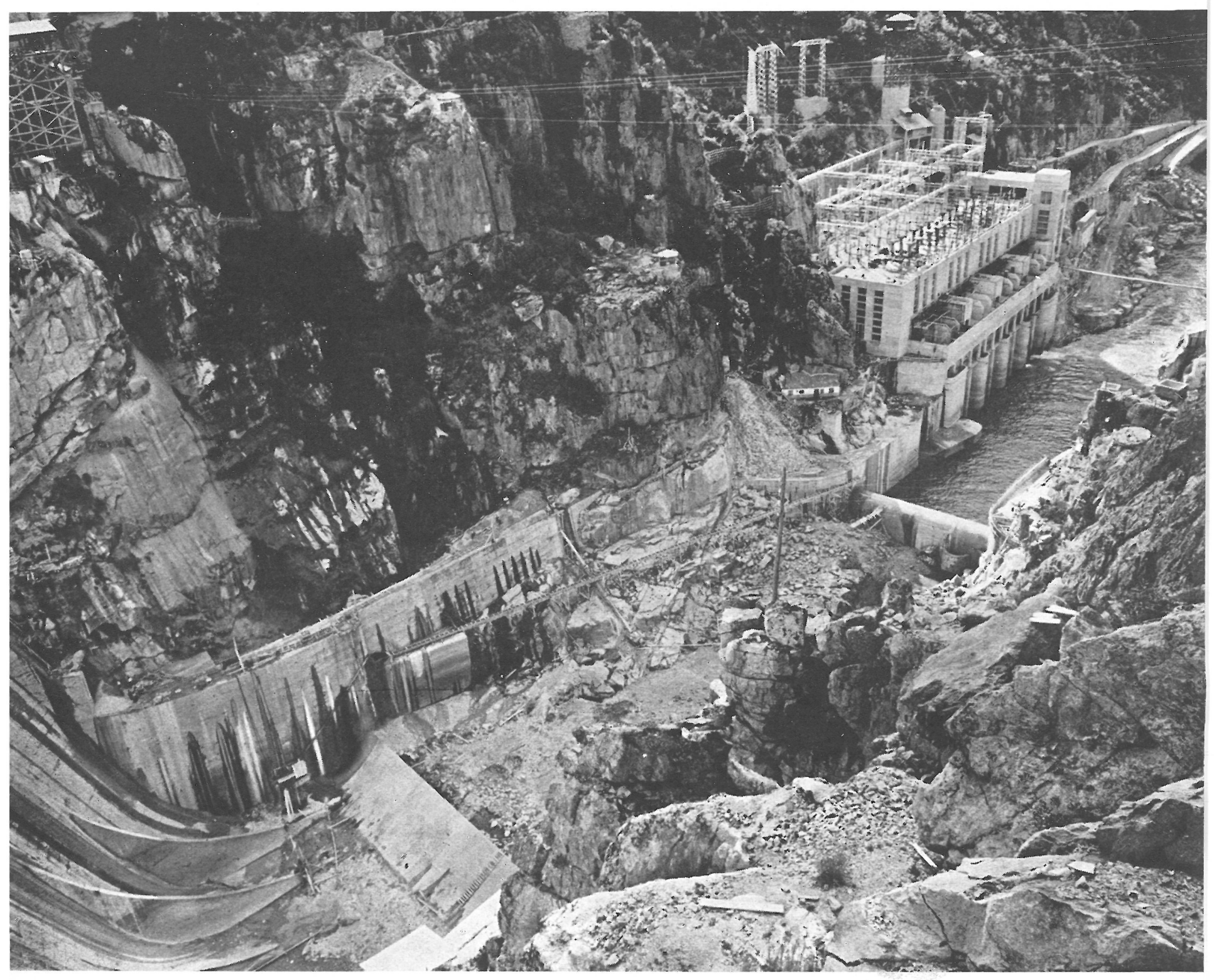

Pie del aliviadero y cuenco de des. trucción de energía. Al fondo: la central.
Para la recepción del cemento a granel en la estación ferroviaria de San Esteban, se construyeron en ésta, que dista dos kilómetros de la obra, tres silos de 6.000 toneladas de capacidad total, y otro, de 2.500 toneladas, en el salto. El transporte del cemento entre la estación y la obra se efectuó por medio de camiones, provistos de recipientes apropiados a esta clase especial de transporte.

J. J. U. 

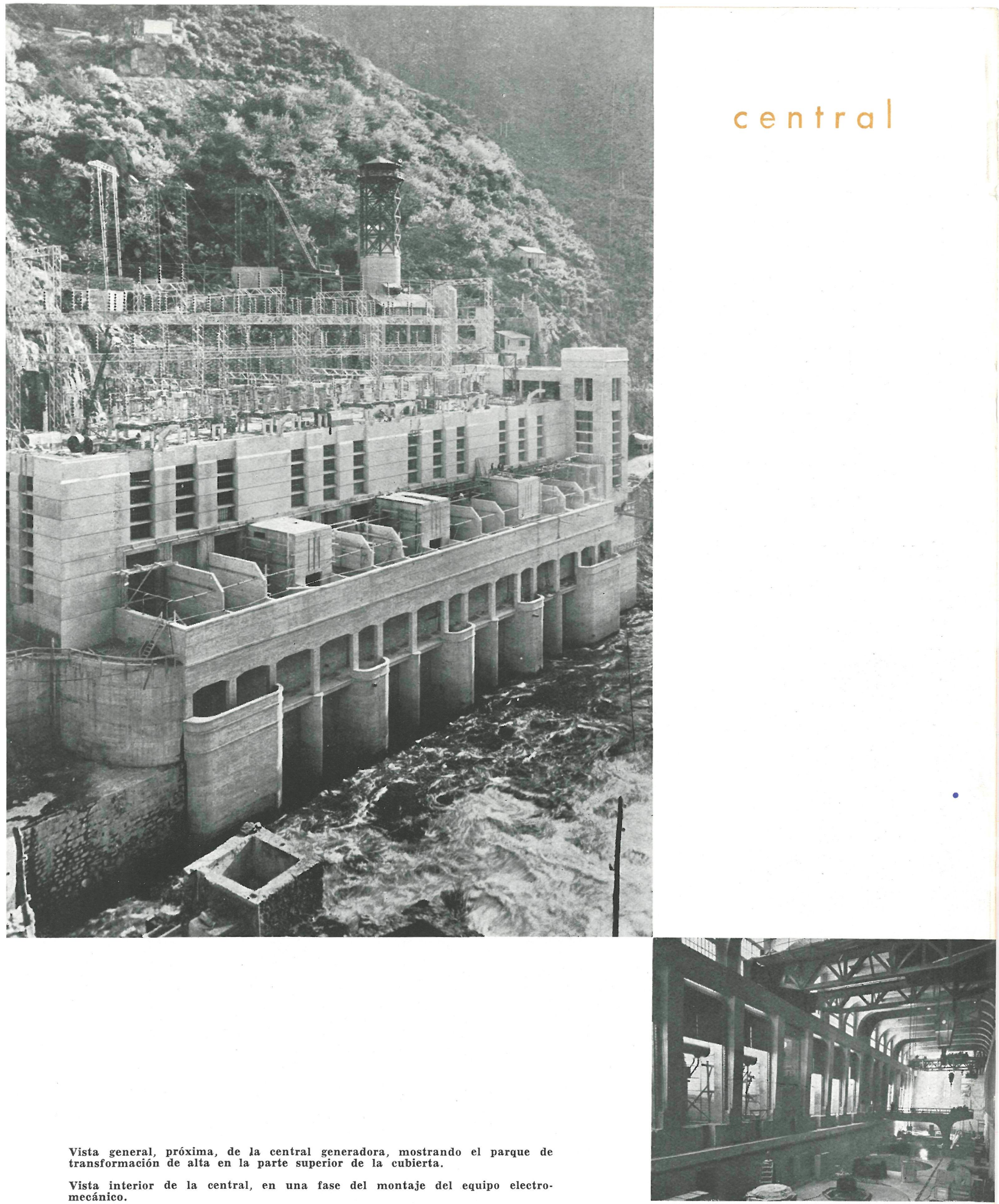

Vista general, próxima, de la central generadora, mostrando el parque de transformación de alta en la parte superior de la cubierta.

Vista interior de la central, en una fase del montaje del equipo electromecánico. 